\title{
NUEVOS DATOS SOBRE LA AUTORÍA DE LA IGLESIA DE SAN PEDRO APÓSTOL DE PEÑAFLOR (SEVILLA)
}

\author{
NEW DATA ON THE AUTHORSHIP OF SAINT PETER \\ THE APOSTLE CHURCH IN PEÑAFLOR (SEVILLE)
}

\author{
José Manuel Higuera Meléndez \\ Grupo de investigación HUM976: Expregráfica. \\ Lugar, Arquitectura y Dibujo. España \\ josemhiguera@gmail.com
}

La iglesia de San Pedro Apóstol de Peñaflor (Sevilla) fue construida entre 1780 y 1798 en el contexto de renovación de la archidiócesis hispalense tras el terremoto de Lisboa. Desde entonces ha ejercido una magnética atracción sobre los historiadores del arte basada en su anómala configuración tipológica respecto de los habituales modelos eclesiales diocesanos y en la incertidumbre que ha venido rodeando a su autoría, atribuida hasta ahora a Antonio de Figueroa. El presente trabajo expone la primera parte de su historia constructiva, que desvela, como dato de mayor interés para la historiografía de la arquitectura sevillana, que el verdadero autor del templo fue el alarife ecijano Antonio Caballero y García.

Palabras clave: iglesia de San Pedro Apóstol; Peñaflor; Antonio de Figueroa; Antonio Caballero; Sancho Corbacho.

Saint Peter the Apostle Church in Peñaflor (Seville) was built between 1780 and 1798, in a context of renewal of the archdiocese of Seville after the Lisbon earthquake. Since then it has exerted a magnetic attraction on art historians, based on its anomalous typological configuration in respect to the usual diocesan ecclesial models and the uncertainty that has surrounded its authorship, attributed up to now to Antonio de Figueroa. The present work expresses the first part of its constructive history, that reveals, as data of greatest interest for the historiography of the Sevillian architecture, that the true author of the temple was the master mason Antonio Caballero y García.

Keywords: Saint Peter the Apostle Church; Peñaflor; Antonio de Figueroa; Antonio Caballero; Sancho Corbacho. 


\section{INTRODUCCIÓN}

Iniciado el último cuarto del siglo XVIII, el caserío de la villa de Peñaflor, localidad de la Vega sevillana del Guadalquivir, ya se concentraba en su mayor parte en la margen izquierda del arroyo de las Moreras, extendiéndose a lo largo de la calle Real y sus tributarias. Los poderes tradicionales, representados por el antiguo castillo almohade, el Ayuntamiento y la iglesia parroquial, se situaban en torno a la Plaza Mayor. Sería por estos años, en el solar que acogió al precedente edificio eclesial gótico-mudéjar, cuando dio comienzo la construcción de la actual iglesia de San Pedro Apóstol, que se prolongaría durante casi dos décadas.

Como una consecuencia lógica de su propia historia constructiva, el espacioso templo ( 42 × $21 \mathrm{~m}$ de planta y $14 \mathrm{~m}$ de altura la nave central, aproximadamente) se encuadra estilísticamente en un barroco tardío en transición hacia el neoclasicismo, reflejando su fábrica exterior destacadas muestras del primero, especialmente en los frentes de buhardillas y en su labrado cuerpo de luces, compuesto por tambor, cúpula y linterna, donde el tradicional ladrillo cortado visto es el gran protagonista. Extrañamente, su apariencia interior es la de una iglesia de salón, tipología inusual en la época en la arquitectura eclesial sevillana, en la cual sus naves presentan un escalonamiento tan leve en altura que impide la entrada de luz a través de la central. El clasicista cuerpo de iglesia, cubierto exteriormente a dos aguas, consta de tres naves de tres tramos bajo bóvedas vaídas, con pilares de planta cruciforme y pilastras de estilo dórico adosadas, ondulando sus frentes los soportes torales. Cuenta con crucero y cabecero planos y capillas colaterales a la mayor, ubicándose detrás de estos tres espacios la sacristía, las servidumbres parroquiales y un patinillo, en tanto a los pies se disponen la capilla bautismal, el coro, la tribuna del órgano y la torre. Y, mientras exquisitas yeserías mixtilíneas y recargados estípites radiales recubren el intradós de la cúpula, un clasicista entablamento dórico enmarca interiormente todo el ámbito del templo.

En justa correspondencia con su monumentalidad, viajeros, escritores e historiadores del arte han venido ponderando sus virtudes estéticas. Así, a los remotos nombres de Tomás López ${ }^{1}, \mathrm{Madoz}^{2}, \mathrm{Baedeker}^{3}$ y Serrano Ortega ${ }^{4}$, hay que añadir, a partir de la segunda mitad del siglo XX, los de distinguidos profesores

\footnotetext{
${ }^{1}$ LÓPEZ, Tomás: Diccionario Geográfico de Andalucía: Sevilla. Granada, 1989, p. 132.

${ }^{2}$ MADOZ, Pascual: Diccionario geográfico-estadístico-histórico de España y sus posesiones de Ultramar. Madrid, 1845-1850 [Valladolid, 1986], p. 128.

${ }^{3}$ BAEDEKER, Karl: Espagne \& Portugal. Manuel du voyageur. Leipzig-París, 1900, p. 332.

${ }^{4}$ SERRANO ORTEGA, Manuel: Guía de los monumentos históricos y artísticos de los pueblos de la provincia de Sevilla. Sevilla, 1911, pp. 133-134.
} 
como Kubler ${ }^{5}$, Morales, Oliver, Pleguezuelo, Sanz, Serrera, Valdivieso ${ }^{6}$, Falcón ${ }^{7}$, $\mathrm{Chueca}^{8}$ y Ollero ${ }^{9}$. Dicha representativa relación queda obligadamente limitada por las características del presente artículo, entre cuyos objetivos, condensados en su título, no está el de ofrecer una relación exhaustiva de las publicaciones y estudios dedicados al templo peñaflorense. En este sentido, sí procede citar una reciente tesis doctoral sobre Antonio de Figueroa que le dedica un capítulo, encuadrando el edificio dentro de la obra construida de dicho maestro ${ }^{10}$. Circunstancia de la atribución a Figueroa en la que dicha investigación coincide con los estudios publicados desde mediados de la pasada centuria.

Ello no es debido sino a que todas estas contribuciones contemporáneas toman como referencia al profesor Antonio Sancho Corbacho, quien en 1952 publicó su investigación sobre la arquitectura barroca sevillana ${ }^{11}$, en la que otorga notable relevancia a la parroquial de Peñaflor. Entre otros datos obtenidos del expediente diocesano, Sancho aporta la cronología de su construcción, atribuyendo el edificio a Antonio de Figueroa, el más activo y prolífico maestro mayor diocesano de la época, nieto del genial Leonardo y último miembro de la saga de arquitectos principiada por este. De esta manera, el dominio de la materia y el rigor investigador del profesor Sancho Corbacho, junto con la falta de nuevas noticias debido al posterior extravío del proyecto, ha llevado a los sucesivos historiadores a admitir y reiterar las concluyentes afirmaciones e hipótesis de aquel, que de manera resumida son las siguientes:

1. En 1773 la primitiva iglesia se hallaba ruinosa debido a los daños causados por el terremoto de Lisboa.

${ }^{5}$ KUBLER, George: Arquitectura de los siglos XVII y XVIII. Madrid, 1957, pp. 308-312.

${ }^{6}$ MORALES, Alfredo J.; OLIVER, Alberto; PLEGUEZUELO, Alfonso; SANZ,

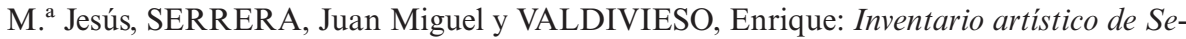
villa y su provincia. T. I. Madrid, 1982, pp. 395-399. También MORALES, Alfredo J.;

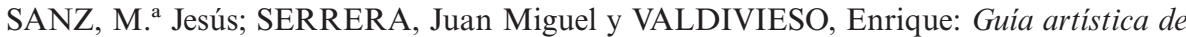
Sevilla y su provincia. Sevilla, 1989, pp. 591-592.

${ }^{7}$ FALCÓN MÁRQUEZ, Teodoro: Historia del Arte en Andalucía. VI. El Arte del Barroco, Urbanismo y Arquitectura. Arquitectura en la Baja Andalucía. Sevilla, 1989, pp. 282340.

${ }^{8}$ CHUECA GOITIA, Fernando: Historia de la arquitectura española. Edad Moderna, Edad Contemporánea. T. II. Ávila, 2001, pp. 485-487.

9 OLLERO LOBATO, Francisco: Cultura artística y arquitectura en la Sevilla de la Ilustración (1775-1808). Sevilla, 2004, pp. 347-382.

${ }_{10}$ NOGALES MÁRQUEZ, Carlos Francisco: El arquitecto Antonio Matías de Figueroa. Tesis doctoral, leída en diciembre de 2015.

11 SANCHO CORBACHO, Antonio: Arquitectura barroca sevillana del siglo XVIII. Madrid, 1952, reed. 1984, pp. 218-222. 
2. En 1778 Pedro de Silva dirigió ciertas obras de reforma, construcción de osario y sepulturas que no se estimaron suficientes.

3. Al decidirse construir un nuevo templo, Antonio de Figueroa fue enviado a Peñaflor a primeros de 1780 y delineó un plano con el perímetro de la nueva iglesia sobre la planta de la primitiva, circunstancia fundamental para la atribución de la autoría del edificio a dicho maestro.

4. El alarife ejecutor de las obras fue el ecijano Antonio Caballero, ayudado por su pariente José Caballero, que labró las portadas.

5. Las obras estuvieron detenidas entre junio de 1788 y 1794 porque se temía la ruina del crucero, corriendo la iglesia peligro de ser derribada.

6. En 1794 José Echamorro reparó y fortaleció el crucero y los arcos torales y sustituyó el orden corintio del interior de la iglesia por el dórico. También construyó el campanario de la torre, que había dejado sin terminar Figueroa.

Sin embargo, la reciente localización y el detenido estudio del expediente diocesano de la obra, junto con la aparición de otros documentos y personajes clave y el estudio de la arquitectura diocesana de la época, han obligado a reescribir el proceso de construcción de la iglesia de Peñaflor ${ }^{12}$, pues se ha podido comprobar que buena parte de las citadas afirmaciones e hipótesis de Sancho Corbacho no son certeras. Entre ellas la hasta ahora indiscutida autoría de Antonio de Figueroa, que aquí se refuta, en lo que constituye una novedosa aportación para la historiografía de la arquitectura tardobarroca sevillana. De este modo, en las páginas que siguen se presenta, cronológica y pormenorizadamente, aunque por fuerza de manera sucinta, el relato de los inicios de la historia constructiva de la actual iglesia de Peñaflor, esenciales para el conocimiento de su verdadero proyectista, acotando aquella entre la primera solicitud de la villa y autorización para la ampliación de la preexistente, hasta la sustitución de Figueroa por el maestro ecijano Antonio Caballero, al cual se considera aquí indiscutible autor del templo. Ello queda corroborado por la hipótesis gráfica de reconstrucción del templo realmente proyectado por Antonio de Figueroa, que se presenta por vez primera, basada en sus detalladas condiciones y en el conocimiento de la arquitectura diocesana ${ }^{13}$, cuya apariencia externa y tipología distan mucho de las del edificio finalmente construido. Así como se exponen las circunstancias que rodearon el apartamiento del reputado maestro mayor y la continuación de los trabajos durante ocho años más sin la supervisión de los alarifes diocesanos, en un caso sin precedentes referido a un edificio de ese porte. Todo ello explica el imposible

${ }^{12}$ HIGUERA MELÉNDEZ, José Manuel: La iglesia de San Pedro Apóstol de Peñaflor (Sevilla). Paisaje, arquitectura y construcción en el contexto clasicista de finales del siglo XVIII. Tesis doctoral inédita, leída el 20 de enero de 2016.

13 Véase la nota 12. 
encaje de la iglesia de Peñaflor en la arquitectura de la diócesis hispalense de finales del XVIII.

\section{MERCED A LA INSISTENCIA DE LA VILLA, LA DIÓCESIS APRUEBA AMPLIAR LA IGLESIA EXISTENTE, PRESENTANDO PEDRO DE SILVA DOS PROYECTOS QUE NO SE EJECUTARÍAN (1773-1778)}

Alcanzado el último tercio del siglo, la vetusta iglesia resultaba pequeña para Peñaflor, que había duplicado su población desde principios de la centuria. El templo, en cambio, no disponía de más espacio para su expansión, al estar rodeado por estrechas calles y por la Plaza Mayor. Además, los contrafuertes realizados entre 1755 y 1756 para afianzar la torre-fachada, debilitada por el terremoto de Lisboa, habían reducido la exigua superficie útil, tanto para los fieles vivos que asistían a misa como para los difuntos enterrados bajo sus solerías ${ }^{14}$. Por todo ello, en los primeros años de la década de 1770, el Ayuntamiento y el clero de Peñaflor demandaron al cabildo eclesiástico hispalense la construcción de nueva iglesia, uniéndose a la legión de parroquias solicitantes. De esta manera, el 14 de marzo de 1773, los capitulares y el clero de Peñaflor denunciaron al arzobispado la estrechez e incomodidad del templo, reclamando una nueva iglesia "capaz, y desente"15.

Comenzaba así el ineludible y parsimonioso proceso establecido para lograr nueva iglesia, lo cual exigiría una buena dosis de constancia ante las reticencias del cabildo eclesiástico. El 11 de octubre de 1777 denuncia la parroquia la aparición de grietas en la capilla bautismal, que obligaron a apuntalarla. Ello animó a las autoridades de la villa a enviar el 13 de enero de 1778 nueva misiva al cabildo, que esta vez sí sería efectiva. De esta forma principiaron los "Autos por la fábrica de Peñaflor sobre el reconocimiento, aprecio y ejecución de las obras de su iglesia" ", proponiendo la diócesis se le dé "la estencion que sea suficiente para el vezindario que oy tiene la espresada villa" y la visita del maestro mayor que estuviese en turno. Recayó este en Pedro de Silva (1710-1784), quien acudió a Peñaflor el 28 de mayo, evacuando un primer informe seis días más tarde. En su escrito restó importancia a las grietas, manifestando el buen estado general y estructural del edificio y justificando la imposibilidad de ampliar el templo por los pies y la cabeza, pues el cuerpo de iglesia iba a resultar "yrrisible a vista de todo

${ }^{14}$ Los feligreses se hallaban molestos por la pérdida en la participación de sufragios que significaría el no poder descansar sus restos mortales en santuario.

15 AMP (Archivo Municipal de Peñaflor), Libro de actas capitulares, cabildo de 14-31773; y AHME (Archivo Histórico Municipal de Écija), AMPE (Archivo Marqueses de Peñaflor de Écija), leg. 105 (años 1772-1773).

${ }^{16}$ AGAS (Archivo General Arzobispado Sevilla), Justicia, Pleitos ordinarios, leg. 10534. 
lo demas". En consecuencia, Silva propuso la ejecución de una nueva iglesia ${ }^{17}$ columnaria de 42 varas de largo por 20 de latitud, de tres naves más una línea de servidumbres al lado de la nave del evangelio, valorando su ejecución en 300.000 reales de vellón ${ }^{18}$.

Sin embargo, la propuesta fue rechazada por su elevado coste, prescribiendo entonces el maestro la reparación de los desperfectos reseñados, la ampliación del osario y profundizar los enterramientos, y ordenando el provisor el 17 de octubre de 1778 que se hicieran las obras con arreglo a esta segunda declaración, que Silva prestó sin necesidad de volver a visitar Peñaflor.

Entretanto, en la villa se produjo el fallecimiento del párroco don Cristóbal Romero de Liñán, que sería sustituido de inmediato por el joven y vehemente don Francisco Javier de Ortega, natural de Écija, quien, a pesar del escaso tiempo durante el que ejerció su ministerio, sería determinante para la construcción de la nueva iglesia. Su designación para Peñaflor implicó también a su protector, el prebendado don Ignacio de Valencia, que ataría lazos con la villa hasta el fin de sus días.

Comenzadas en marzo de 1779 las obras prescritas por Silva, un nuevo imprevisto vendría a paralizarlas, ya que no se podía ejecutar la excavación de tierras por encontrar piedra muy superficial. El provisor ordenó el 17 de abril de 1779 la visita de Antonio de Figueroa a Peñaflor a fin de resolver las dificultades aparecidas. Figueroa, que por aquel entonces llevaba trece años trabajando en obras diocesanas y ya contaba en su haber con notables realizaciones ${ }^{19}$, acudió presto a Peñaflor, donde el 21 de abril pasó recibo por su visita de reconocimiento.

$17 \mathrm{Al}$ contrario de lo que hizo en Algodonales apoyando el proyecto de ampliación de la iglesia de José Álvarez, el cual adolecía de graves desproporciones entre las partes del templo, Pedro de Silva cambió su timorata actitud en Peñaflor, optando por la propuesta de construcción de una nueva iglesia, si bien no presentó plano ni condiciones.

${ }_{18}$ Silva, quizá demasiado influido por el preexistente edificio gótico-mudéjar, planteaba para Peñaflor una iglesia de tres naves también con columnas de mármol y cubiertas de madera, elementos que ya había utilizado por separado en su sevillano templo de San Roque (1760-1763) y en el de San Sebastián de Marchena (1762-1768). El maestro mayor proponía una iglesia con capilla mayor y dos colaterales a esta, sin crucero ni cúpula central, disponiendo todas las servidumbres en la gualdera norte y recayendo a la Plaza Mayor, por tanto, una limpia fachada en la que habría ocasión para el lucimiento en portada, buhardillas y torre.

19 Aunque hasta 1776 no obtuvo el nombramiento oficial de maestro mayor del arzobispado de Sevilla, Antonio de Figueroa lo era oficiosamente desde 1772, seis años después de comenzar como asentista en las obras arzobispales. Entre las realizaciones diocesanas del maestro en sus dos estatus hasta su llegada a Peñaflor destacan: la ampliación de la iglesia de La Campana mediante la construcción de la nave del evangelio y su portada de piedra (1767-1771), la espadaña de la parroquial de Algámitas (1768), la iglesia de Villanueva de las Cruces (1768-1770), la ampliación y portada principal de la parroquial 


\section{ANTONIO DE FIGUEROA DA LAS TRAZAS Y CONDICIONES PARA EL NUEVO TEMPLO. SIN EMBARGO, LA IGLESIA CONSTRUIDA NO RESPONDE A SU PROYECTO (1779)}

Tras haber girado visita a Peñaflor, Antonio de Figueroa hizo su declaración el 5 de mayo de $1779^{20}$. En ella reconoció no encontrar modo de ampliar la iglesia sin que siguiese con la incomodidad actual, por lo que se decidió "a formar Plano, Condiciones y Aprecio, para la Construccion de Nueva Yglesia”. El maestro mayor estimó el terreno que se necesitaba, adjuntando un plano de planta, o traza, del nuevo edificio que complementaba con las condiciones para su ejecución ${ }^{21}$ y para el derribo de la primitiva iglesia gótico-mudéjar.

La lectura de dichas condiciones determina que Figueroa proyectó para Peñaflor un templo exento de tres naves y planta rectangular, de 48 varas y media de longitud por algo menos de 24 de latitud, cubriéndose la nave central con bóveda de cañón y las laterales por arista, y disponiendo sencillos pilares con pilastras adosadas recayentes a la nave mayor ${ }^{22}$ y tambanillos hacia las gualderas. Cuerpo de iglesia de tres tramos, seguidos del crucero, capilla mayor y colaterales a esta, ubicándose detrás la sacristía y el resto de servidumbres y a los pies de la iglesia la capilla bautismal, el coro y tribuna del órgano y la torre. Decoración interior en orden dórico, quedando cubierto el crucero con una media naranja trasdosada mediante cubierta de teja de planta ochavada. La altura de la caña de la torre igual a la del caballete de la nave mayor, incluida la imposta de arranque del cuerpo de campanas, subiendo este cinco varas, medida del lado de su planta,

de Campillos (1771-1774), el proyecto previo para la nueva iglesia de Algodonales (1773), la reforma del Palacio Arzobispal (1775-1776 y 1779-1780), la terminación desde cornisas, portadas y campanario de la iglesia de Zahara de la Sierra (1775-1779), la linterna de la bóveda del crucero de la carmonense iglesia de San Pedro (1776), el proyecto de ampliación y nueva torre para la parroquial de Bollullos del Condado (1776), el proyecto definitivo para la iglesia de Algodonales, con José Álvarez, incluyendo la magnífica portada de cantería (1777), el campanario y portadas de la iglesia de Coria del Río (1777-1779), el proyecto para rematar la torre de San Pedro de Carmona (1777), la dirección de obra de la ecijana torre de San Gil (1779), el proyecto de las cubiertas de la iglesia de la Asunción de Aracena (1779), el de reconstrucción de la parroquial de Bormujos (1779) y la dirección de obras de la capilla sacramental de Santa Bárbara de Écija (1779).

${ }^{20}$ AGAS, Justicia, Pleitos ordinarios, leg. 10534, ff. 36r-45v. Visita en la que se conocerían Antonio de Figueroa y el cura don Francisco Javier de Ortega.

${ }^{21}$ Dicho plano de planta se ha perdido. Sin embargo, el minucioso pliego de condiciones redactado por el maestro, junto con el conocimiento adquirido sobre las iglesias del barroco diocesano dieciochesco, posibilitará la formulación de una hipótesis gráfica personal que reconstruya, en el sentido de unir ideas para completar su conocimiento, el edificio proyectado por Antonio de Figueroa para Peñaflor.

${ }^{22}$ Al contrario de lo establecido por Pedro de Silva, Antonio de Figueroa proyecta una iglesia con pilares de fábrica de sección rectangular. 
altura en la que se distribuye el orden toscano, con vuelos de ladrillo cortado en limpio. Sobre dicho cuerpo, banco cuadrado, rebanco ochavado, aguja alicatada con piezas cerámicas vidriadas blancas y azules, cruz y veleta y sobre el banco elementos vidriados a eje con las pilastras inferiores. Escalera interior de ojo abierto, dando acceso a la tribuna y al cañón dispuesto para las pesas del reloj ${ }^{23}$, todo lo cual debía disponerse "con buen Arte y Zimetria, Dexandolo enlucido y rematado a una buena perfeccion".

Por lo demás, jerarquización volumétrica exterior, con ventanas en los muros de la emergente nave mayor, tejada a dos aguas, mientras que las menores se cubren a un agua y los brazos de crucero y cabecero a tres. Figueroa propone atirantar la fachada de los pies con la del pósito de la villa ${ }^{24}$ y establecer la proporción sesquiáltera ${ }^{25}$ en los arcos que dividen las naves, contándose 14 varas y tres cuartas desde el pavimento de la iglesia hasta la clave del cañón de la nave central, es decir, tres cuartas de vara más que la referida proporción sesquiáltera.

Por lo que respecta a las naves menores, de cinco varas de ancho, tienen a ocho varas de altura las claves de sus bóvedas por arista ${ }^{26}$, cubriéndose las dos capillas colaterales al altar mayor con bóvedas vaídas. Enmaderados en la estructura de cubierta, y cornisas exteriores "ametaladas, entre limpio y entallado"27, ventilándose las maderas mediante buhardas y buhardillas.

${ }^{23}$ Antonio de Figueroa repite en su proyecto de Peñaflor el esquema que ya utilizó en Algodonales para ubicar la caseta del reloj y conseguir un elevado cañón para el descenso de las pesas.

${ }^{24}$ Por tanto, su primera intención fue alinear la fachada de los pies con la del pósito municipal.

${ }^{25}$ También llamada "del cuadrado y medio", en la que la relación alto/ancho es $3 / 2$, era esta una de las proporciones más frecuentemente aplicadas por los maestros mayores del arzobispado de Sevilla en el trazado de los templos. Figueroa la utilizaría, por ejemplo, en los arcos que separan las naves de las iglesias parroquiales de Manzanilla y de San Bartolomé de Sevilla.

${ }^{26}$ En este caso, los "zinchos" de las bóvedas a que se refiere el maestro Figueroa son los arcos fajones de ladrillo tosco que dividen en tramos y dan refuerzo y rigidez estructural al sistema de abovedamiento tabicado de las naves menores. Dichos arcos fajones se apoyan en las correspondientes impostas situadas en la gualdera y en el pilar frontero, que descansan a su vez sobre los tambanillos, piezas resaltadas del paramento, formadas generalmente por rectángulos y otras de contorno mixtilíneo similares a pinjantes. Al no cumplir aquí función estructural alguna, son denominados por Antonio de Figueroa "tambanillos fingidos".

${ }^{27}$ Se prescribía este tipo de cornisas para ahorrar en ladrillo limpio, completándose el molduraje mediante el "tallado" in situ, aterrajando el mortero de cal y arena. Ametalar es un verbo en desuso que significa "formar algo con mezcla de cosas heterogéneas" (Diccionario de la lengua española, $23^{\mathrm{a}}$ edición, octubre de 2014). También se usa como "mezclar dos cosas en igual proporción”. 
En cuanto a las dos portadas, se construirían en cantería, en orden dórico, "concluyendolas con sus frontis y remates, sin atender a mas Adornos que es, a lo mas permanente, vistoso y bien executado" 28 . Osario cubierto con puerta a la calle y retrete "poniendole su Asiento como es estilo". Toda esta nueva obra habría de quedar "enlucida y rematada a su Correspondiencia" y acabadas sus paredes exteriores "con Cal Delgada, y Blanqueadas con la de Moron, Ymitadas de Canteria, a fin de la mayor permanencia”. Figueroa presupuestó las obras en 263.725 reales de vellón, cantidad que ascendería hasta los 350.000 al incluir la cimentación y los enmaderados.

La descripción general de la iglesia trazada por Figueroa para Peñaflor muestra lo alejado de su arquitectura con el actual edificio parroquial. Ajustándose, eso sí, a la tipología eclesial diocesana dieciochesca para templos de tres naves ${ }^{29}$ en sus tres aspectos fundamentales: la jerarquización volumétrica de los espacios, con la prominente nave central; la ejecución sobre el crucero de una sencilla media naranja sin tambor ni linterna con faldones de teja; y un cuerpo de campanas con pilastras toscanas en sus frentes, coronado por un chapitel piramidal revestido de azulejos y rematado en sus esquinas con piezas vidriadas. En la actual iglesia de Peñaflor, las tres naves se cubren con un tejado a dos aguas, sin que exista entre ellas desfase alguno en altura. Una original cúpula sobre un labrado tambor y coronada por una artística linterna cubre el crucero. Y un esbelto y proporcionado campanario de tres cuerpos telescópicos y cupulín, dotado de un amplio repertorio de columnas, pilastras, capiteles y remates cerámicos, parece elevarse etéreamente.

Las diferencias tipológicas son evidentes, pues en lugar del habitual aspecto basilical, la iglesia de Peñaflor presenta, como se dijo, disposición de iglesia de salón, de naves apenas escalonadas en altura, en la que el soporte aislado, bajo bóvedas vaídas, sustituye como elemento estructural a la línea de carga conformada por la danza de arcos del tipo diocesano, penetrando la luz natural desde las gualderas de las naves laterales, en lugar de hacerlo a través de la nave central.

${ }^{28}$ Expresión muy parecida a la que utilizó en sus condiciones para labrar las portadas de la ecijana iglesia de Santa María ("Las dos dichas Puertas deveran ser adornadas con sus Cuerpos de Arquitectura sujetos a la distribucion del Orden dorico, assi en sus Pedestales, Vazas, Pilastras, Capiteles, Alquitrave, frizo y Cornisa, con la diferencia que la principal se rematará con un segundo cuerpo colocándose en el el Orden Jonico, y la menor con su frontis, y assi a la una como a la otra se le pondran sus remates en aquellas partes que corresponde". AGAS, Justicia, Pleitos ordinarios, leg. 10691, ff. 356r-365v, 3-11-1780), que sin embargo se cuentan entre las de mayor barroquismo de Antonio de Figueroa. No sería extraño, por tanto, que en Peñaflor hubiera ocurrido igual, a pesar de la apariencia desornamentada a que inducen las condiciones.

${ }^{29}$ Y que el maestro ya había llevado a la práctica en Zahara de la Sierra, Manzanilla y San Bartolomé de Sevilla. 
El escaso parecido del edificio planeado por el maestro mayor con el que hoy se levanta en la villa lleva ineludiblemente a concluir que el templo para el que dio su traza Antonio de Figueroa no es el que finalmente se construyó ${ }^{30}$, aunque el análisis e interpretación de sus minuciosas condiciones, junto con la comparación con otras iglesias de tres naves en las que trabajaba el maestro coetáneamente al encargo de Peñaflor, han permitido formular una hipótesis gráfica de su proyecto, utilizando elementos constructivos y detalles ornamentales tomados de la propia obra construida de Antonio de Figueroa. El resultado de dicho ejercicio, que aquí se expone, se identifica plenamente con los templos del barroco diocesano hispalense.

\section{UNA POLÉMICA CON LOS CIMIENTOS DEL NUEVO TEMPLO CAUSA EL DEFINITIVO APARTAMIENTO DE FIGUEROA DE LAS OBRAS Y SU SUSTITUCIÓN POR ANTONIO CABALLERO COMO PROYECTISTA Y MAESTRO EJECUTOR (1779-1780)}

La demolición de la antigua iglesia se completó entre octubre y noviembre de 1779, ya que a mediados de diciembre estaban abriéndose los cimientos del nuevo templo. Ejecutaba las obras el alarife Alonso Sánchez, quien iba a verse envuelto en una polémica que, además de costarle el puesto, provocaría también el apartamiento de Antonio de Figueroa de la obra de Peñaflor. A partir de entonces, esta quedaría en manos de su director y administrador, el párroco don Francisco Javier de Ortega.

El 16 de diciembre, el Ayuntamiento procedió a incoar expediente contra el alarife de la obra por introducirse con los cimientos en la plaza pública y adelantarse hacia las casas de un vecino denunciante ${ }^{31}$.

${ }^{30}$ Como se verá, la iglesia construida en Peñaflor no siguió la traza ni las condiciones de Figueroa, ni las de ningún otro maestro mayor de la diócesis.

${ }^{31}$ La disputa se originaría realmente cuando, siguiendo lo establecido en el pliego de condiciones, el maestro Alonso Sánchez prolongó la excavación de los nuevos cimientos de la gualdera sur hasta la tirantez de la fachada del pósito municipal, avanzando veintidós pies (siete varas y tercia) respecto de la antigua iglesia hacia la fachada de la casa del denunciante, ámbito ocupado antes por una plazoleta. Los cimientos, además, se habían excavado seis pies (dos varas) fuera de la línea sur del viejo templo, en terrenos de la Plaza Mayor, tratándose por tanto de obras ilegales. Dicha orden le sería dada a Alonso Sánchez por el párroco don Francisco Javier de Ortega, y respondería a sus deseos de disponer de una iglesia más capaz, ya que esas dos varas son las que tiene la iglesia finalmente construida de más, también en su longitud, respecto de la proyectada por Figueroa -la iglesia construida tiene 50,48 x 25,72 varas, mientras que Figueroa proyectó su templo de 48,50 x 23,83 varas-. El denunciante, sintiéndose perjudicado en sus intereses, interpuso denuncia contra el maestro de la obra, solicitando la paralización de los trabajos y amenazando a maestro y oficiales con importantes penas. Dicho vecino pretendía que la iglesia se ajustara 
Formalizada la denuncia contra Alonso Sánchez, se solicitó su asistencia el día siguiente al reconocimiento de los supuestos perjuicios causados, habiéndose nombrado como perito tercero al maestro Alonso Ruiz Florindo, residente en la vecina Palma del Río ${ }^{32}$. Sin embargo, Sánchez no acudió al reconocimiento, declarando Ruiz Florindo que la cimentación se había introducido en la plaza seis pies (dos varas) hacia el mediodía, además de desplazarse hacia el costado de poniente de la plaza, "quitandoles las luces" al vecino denunciante y a otros.

Alonso Sánchez hizo caso omiso del mandato judicial que prohibía continuar la obra en terrenos ajenos, volviendo a alterar las líneas dos días más tarde, aunque fue sorprendido por unos vecinos que pusieron los hechos en conocimiento de la autoridad. Tras esta nueva desobediencia del maestro de la obra, se emitió auto contra él, siéndole impuesta una multa de diez ducados, además del pago de costas y salario del perito.

Ajenos a la polémica en Sevilla, el provisor ordenaba que Antonio de Figueroa pasase a Peñaflor a comprobar la apertura de los cimientos, llegando aquel a primeros de febrero de 1780, momento en que conoció las disensiones existentes entre la fábrica parroquial, los vecinos reclamantes y el municipio. Figueroa supo entonces de la denuncia interpuesta contra el maestro de la obra, causada por la pretensión del párroco de alterar el proyecto para construir una iglesia mayor que la autorizada por el cabildo. El maestro mayor discutiría acaloradamente con el cura don Francisco Javier de Ortega y además de visitar al mayordomo de la fábrica, es posible también que se entrevistara con el vecino denunciante. El día 9 de dicho mes, el Ayuntamiento solicitó que prosiguiera la obra "segun lo que apetece este vesindario", dejando señalado el sitio tanto de la iglesia como de la torre, y si fuera preciso tomar "algun terreno Realengo con vista de la demarcacion acordara la villa lo condusente para fasilitar la correspondiente lisensia y cortar de este modo las contiendas que se an promovido"33.

a los límites de la antigua. Además, como procurador y antiguo munícipe, era conocedor del delito que significaba la usurpación del terreno público.

${ }^{32}$ Se trata de Alonso Ruiz Florindo de Carmona (1753-1793), alarife perteneciente a la prolífica familia originaria de Fuentes de Andalucía, cuya obra de mayor envergadura es el pósito de la localidad. En 1771 se casó con María Fernández y "una década más tarde se encuentra afincado en Palma del Río, dedicado también a obras de arquitectura". OLLERO LOBATO, Francisco y QUILES GARCÍA, Fernando: Fuentes de Andalucía y la arquitectura barroca de los Ruiz Florindo. Fuentes de Andalucía, 1997, pp. 118-119.

${ }_{33}$ AMP, Libro de actas capitulares, 9-2-1780, leg. 4. La solicitud del arzobispado para poder tomar los terrenos públicos que requería la construcción de la nueva iglesia debió de llegar a principios de febrero. El Ayuntamiento, que hasta entonces no se había pronunciado ante la ejecución de obras ilegales en sus propias narices, esgrimiendo ahora la utilidad pública del nuevo templo, instó a la continuación de las obras, ofreciéndose a facilitar la correspondiente licencia para ceder los terrenos realengos necesarios. De esta manera, también "desactivaba" la denuncia por ejecución de obras ilegales. 
Posiblemente el temor a ser también denunciado, originaría que en el plano dibujado y firmado el día 15 de febrero por Antonio de Figueroa, en contra de lo que había prescrito en su pliego, el contorno de la iglesia proyectada aparezca totalmente desplazado hacia la cabecera. Este retranqueo de nueve pies (tres varas) ampliaba el espacio frontero a las casas del denunciante, aunque también implicaba que la fachada de los pies ya no iba a quedar atirantada con la del pósito municipal, que era una de las premisas de su proyecto.

El 16 de febrero, ya en Sevilla, Antonio de Figueroa presentó ante la Diputación de Negocios del cabildo metropolitano un escrito hasta ahora inédito, en el que suplicaba ser escuchado, pues no había dado motivos para que sus miembros desconfiasen de su conducta. Cuenta Figueroa cómo pasó a rendir visita al prebendado don Ignacio de Valencia, explicando lo acontecido con su pupilo, el párroco de Peñaflor, quien por su parte declaró ante el cabildo "atropellando la estimacion del Suplicante, y abatiendo la de aquel Pobre y desdichado Maestro que por V.S. fue encargado en la Construcion de aquella Obra".

Si en un primer momento Antonio de Figueroa recibió el apoyo del cabildo y del prebendado don Ignacio de Valencia en la exposición de lo ocurrido, la comparecencia de don Francisco Javier de Ortega en la que daría cuenta de la discusión con el maestro mayor, declarando posiblemente que este había modificado las condiciones de la iglesia tras entrevistarse con el denunciante, harían al cabildo recelar de la actuación de Antonio de Figueroa, a quien le sirvió de poco esgrimir la delineación del conocido plano que muestra la situación y distribución de la iglesia antigua y el perímetro de la nueva.

La hostilidad surgida entre el párroco y Antonio de Figueroa podía echar a perder la construcción del nuevo templo. Por esta razón, y quizá para evitar tener que desautorizar a su maestro mayor, el cabildo decidió hacer borrón y cuenta nueva, apartando de la obra tanto a Antonio de Figueroa como a Alonso Sánchez, que fueron enviados a otros destinos ${ }^{34}$. Dado que don Francisco Javier de Ortega, como director y administrador de las obras tenía facultad para nombrar maestros de su satisfacción, sería en este momento cuando solicitaría los servicios de su paisano Antonio Caballero y de otros alarifes ecijanos ${ }^{35}$. Además, las influencias del prebendado don Ignacio de Valencia persuadieron al cabildo para que le fuera encomendada en comisión particular la supervisión de la construcción

${ }^{34}$ Antonio de Figueroa estuvo ocupado los siguientes meses con la parroquial de Coria del Río y las de San Bartolomé y Santiago de Carmona.

${ }_{35}$ Caballero declararía "que quando fue llamado para construir dicha obra, solo se le manifestó berbalmente por el Director, hasta donde se havia estender, con la Longitud y Latitud de toda la Yglecia, tomando de la Plaza, cierto sitio con la annuencia de las Justicias", replanteando la iglesia "harreglada al terreno que se havia demarcado para ella". AGAS, Justicia, Pleitos ordinarios, leg. 10534, ff. $214 \mathrm{r}^{\text {bis }}-219 \mathrm{v}$ y $220 \mathrm{r}-225 \mathrm{r}$. 
de la iglesia ${ }^{36}$, que a partir de entonces no volvería a ser visitada por los maestros mayores de albañilería de la diócesis hasta $1794^{37}$.

El día 21 de febrero dio el Ayuntamiento de Peñaflor su respaldo a la construcción del nuevo templo, pues lo importante era que "el pueblo logre una Yglecia capaz, y suficiente para ese vesindario" ${ }^{38}$. De esta manera, poco después el Ayuntamiento concedió el terreno de la Plaza Mayor que solicitaba don Francisco Javier de Ortega para la nueva iglesia ${ }^{39}$.

La trascendencia de este episodio estriba en que no solamente alteró el proceso constructivo del templo, pues el apartamiento de Alonso Sánchez requirió la presencia de un nuevo maestro ejecutor, Antonio Caballero, que dirigiría y ejecutaría las obras en solitario, huérfanas ya de la supervisión de los maestros mayores diocesanos, como declararía en 1794 Fernando Rosales ${ }^{40}$. El incidente también afectó de manera decisiva a la traza original proyectada por Antonio de Figueroa, cuyas dimensiones serían ampliadas por el cura don Francisco Javier de Ortega, con las consiguientes variaciones en sus proporciones, en las superficies

${ }^{36}$ Don Ignacio de Valencia declararía que, "suplicandome los dichos s. ${ }^{\text {res }}$ de la Diputacion que estuviese a la vista en las ocaciones en que iva al Referido Pueblo de Peñaflor y diese las ordenes que tuviera por combeniente al seguimiento y forma de dicha Yglecia”. AHPS (Archivo Histórico Provincial de Sevilla), Fondo de Protocolos Notariales, sig. 13220 , of. 19 , libro $1^{\circ}$ de 1805 , ff. 573r-589v. Don Ignacio de Valencia otorga su primer testamento. Sevilla, 29-4-1805. Es el único caso que conozco en que la diócesis haya delegado en manos ajenas una obra de semejante envergadura, hasta el punto de evitar las inspecciones de los maestros mayores de albañilería durante toda su ejecución.

37 Al visitar la obra en enero de 1794, el maestro Rosales denunció "la Ruina que en ella se advierte, lo que se huviera remediado si se hubiera vicitado en los tiempos competentes, como son estando hecha la Canal o sangeo de los simientos, al tiempo de su formacion (que es la mas precisa y que menos se executa), construcion de Yntercolunios y Votales, y a la colocacion de su cubierta o cerramento de obra". Concluyendo, tras leer el pliego de condiciones de Figueroa, "que la citada obra se ha executado a el libre alvedrio del Maestro que la hizo porque en ella no se encuentra cosa que combenga con las citadas condiciones, de que resulta los muchos gastos que van imbertidos, y la Ruina que en ella se advierte", lo que se habría evitado de haberse visitado en su momento. AGAS, Justicia, Pleitos ordinarios, leg. 10534, ff. 204r-209v.

${ }^{38}$ AMP, Libro de actas capitulares, 21-2-1780, leg. 4.

39 AMP, Libro de actas capitulares, 19-11-1794. Inédito. El Ayuntamiento, reunido en cabildo, trató sobre el "Pedimento presentado por el D. ${ }^{\mathrm{r}}$ D. ${ }^{\mathrm{n}}$ Ygnacio de Valencia Presv. ${ }^{\mathrm{o}}$ y prebendado de la s. ${ }^{\text {ta }}$ Yglecia de Sevilla con la Supp. ${ }^{\text {ca }}$ de que se le dé Testimonio y Copia a la letra de Carta que de Orden del Ylt. ${ }^{\text {mo }}$ Cavildo Ecclesiastico de dicha s. ${ }^{\text {ta }}$ Yglecia se dirigio a la Justicia de esta V. ${ }^{\mathrm{a}}$ dando gracias por la consecion de Varas de Terreno que se tomaron de la Plaza", acordando "que el presente ss. ${ }^{\text {no }}$ busque en los Libros Capitulares respectivos la Carta de que se hace referencia y con su insercion y del Cavildo que se Ubiere Celebrado se dé a el D. ${ }^{\mathrm{r}}$ D. ${ }^{\mathrm{n}}$ Ygnacio Valencia el Testimonio que Solicita”.

40 Véase nota 37. 
de sus diferentes espacios y en los costes de ejecución. Caballero, aunque gozaba de notable prestigio en su ciudad natal, adolecía de falta de experiencia como proyectista de iglesias, de manera que la principal consecuencia de la ausencia de control de las obras por parte de los alarifes diocesanos iba a consistir en la anómala tipología adoptada para el nuevo edificio por Caballero. Y ello no fue sino la consecuencia directa de intentar adaptar a los requerimientos del párroco la planta trazada por Figueroa, distorsionándola, junto con el deseo de seguir miméticamente las pautas constructivas de las coetáneas obras de Santa Cruz de Écija, patria chica de cura y alarife. En un determinado momento, ya bien avanzada la construcción, se vería la imposibilidad de continuar con las alturas que establecía el modelo astigitano. Tal circunstancia obligó a Caballero a reducir la elevación de las naves, haciendo arrancar al mismo nivel sus arcos formeros y fajones. De esta manera, se disminuyó la diferencia de altura entre la nave central y las laterales, lo cual explica la rara apariencia de hallenkirche o iglesia de salón del templo, que lo aleja completamente de los habituales modelos constructivos arzobispales. Por esta razón, la arquitectura de la iglesia de San Pedro Apóstol de Peñaflor ha estado envuelta en un halo de misterio, desvelado ahora al conocerse su verdadero autor, pues cuando en 1788 las obras quedaron paralizadas, al maestro Antonio Caballero únicamente le restaba por labrar el cuerpo de campanas, finalizado posteriormente por José Echamorro.

Fecha de entrega: 30 de octubre de 2018

Fecha de aceptación: 1 de julio de 2019 


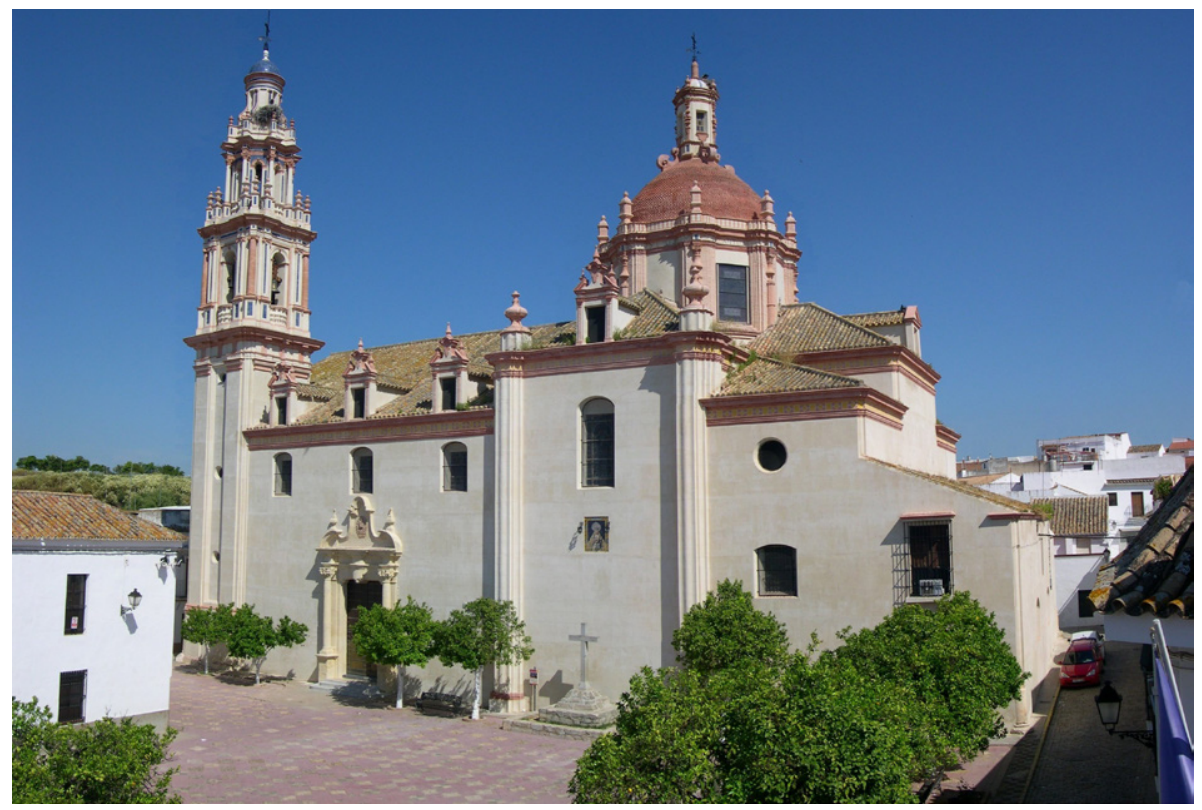

Figura 1. Vista actual de la iglesia de San Pedro Apóstol de Peñaflor. Foto: José Manuel Higuera Meléndez.

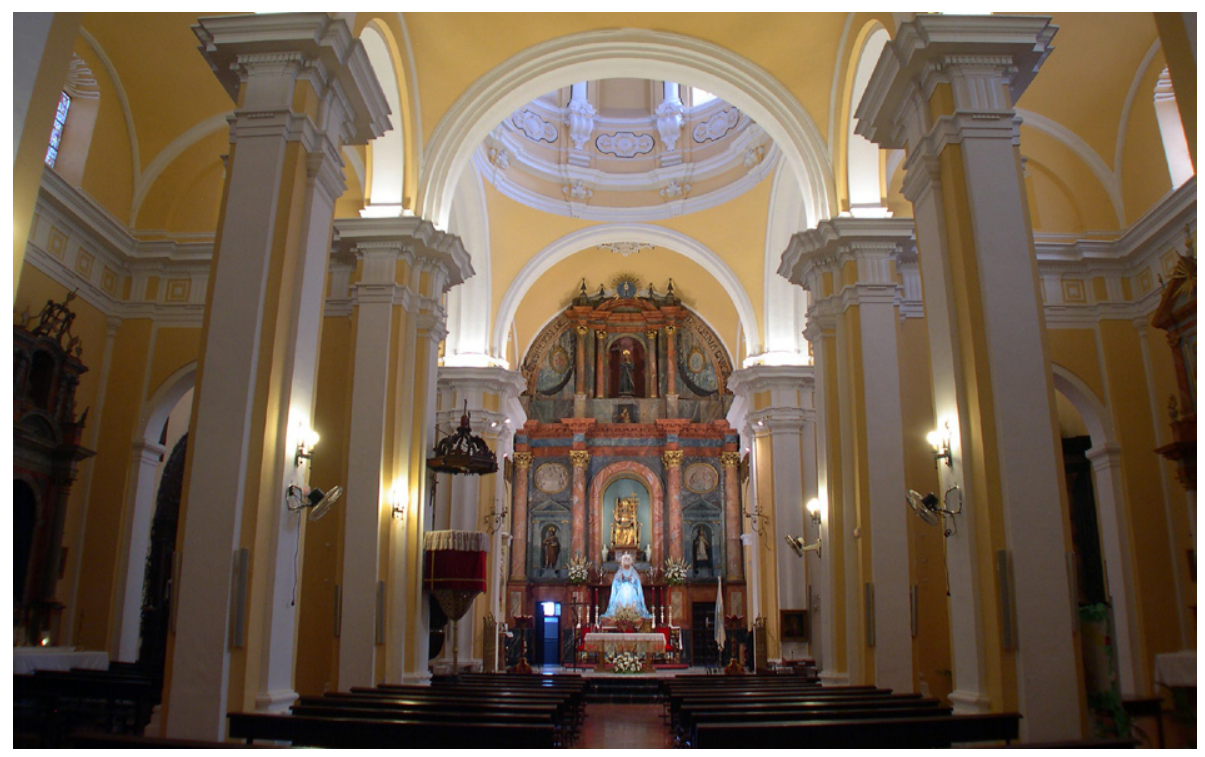

Figura 2. Interior del templo. Foto: José Manuel Higuera Meléndez. 


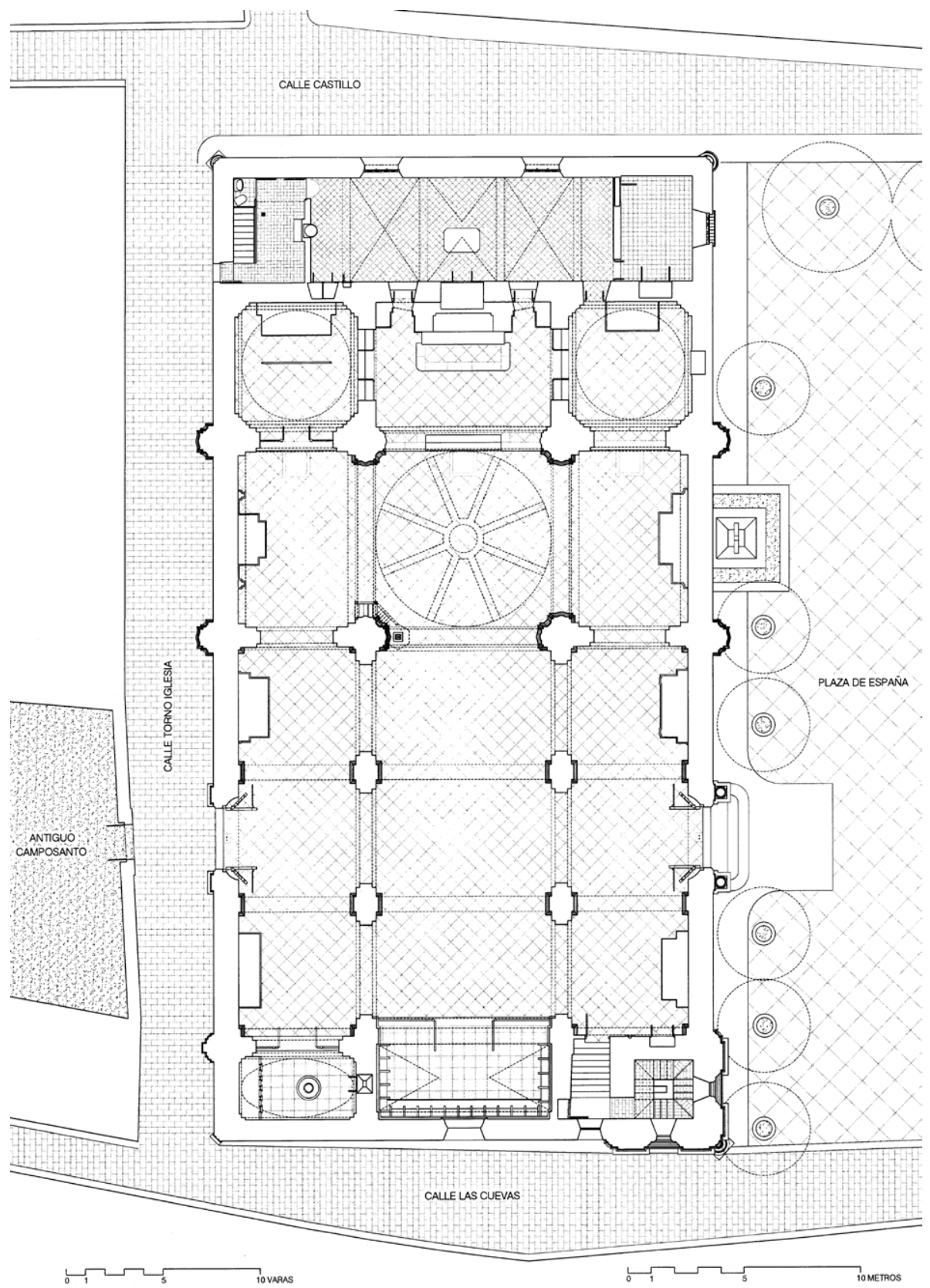

Figura 3: Planta actual. Dibujo: José Manuel Higuera Meléndez. 

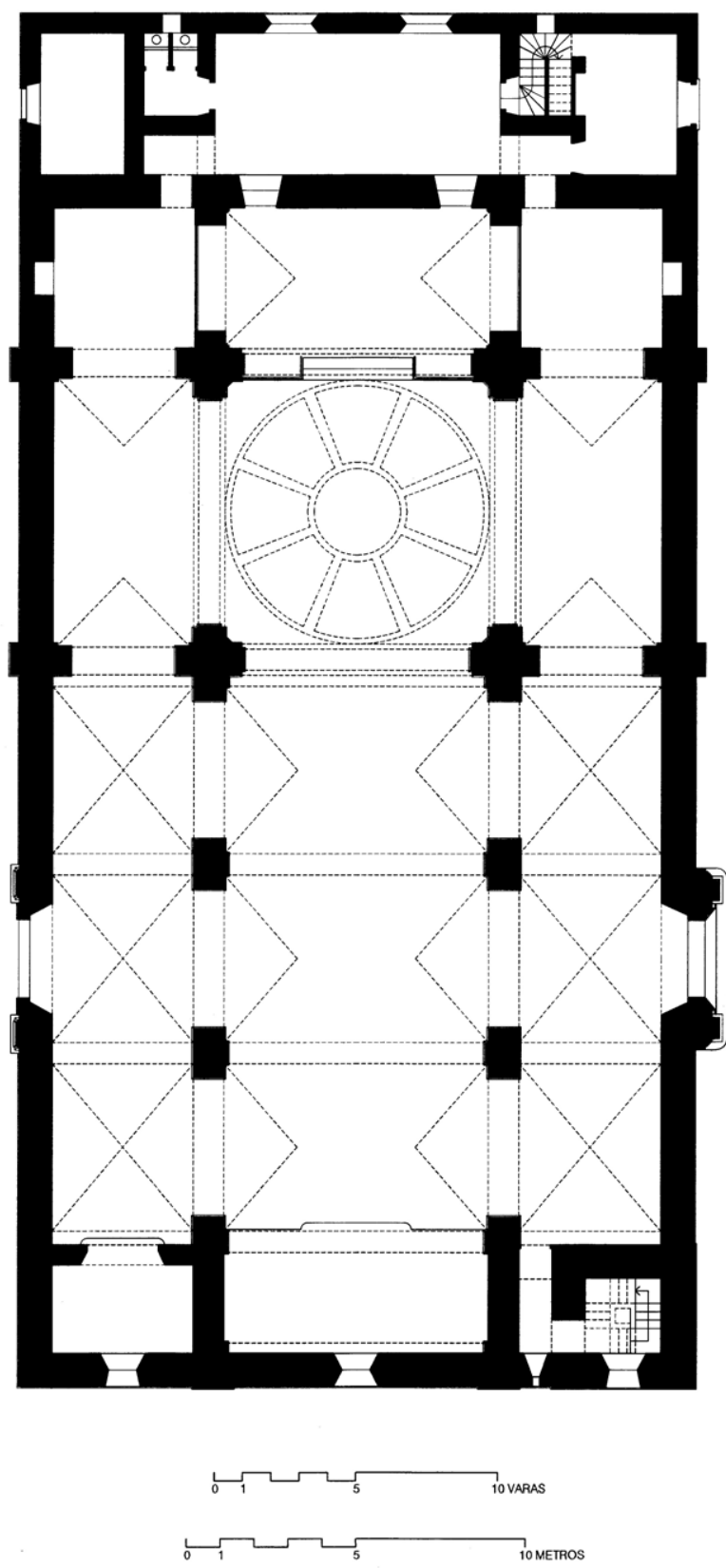

Figura 4. Planta hipotética trazada por Antonio de Figueroa. Dibujo: José Manuel Higuera Meléndez. 


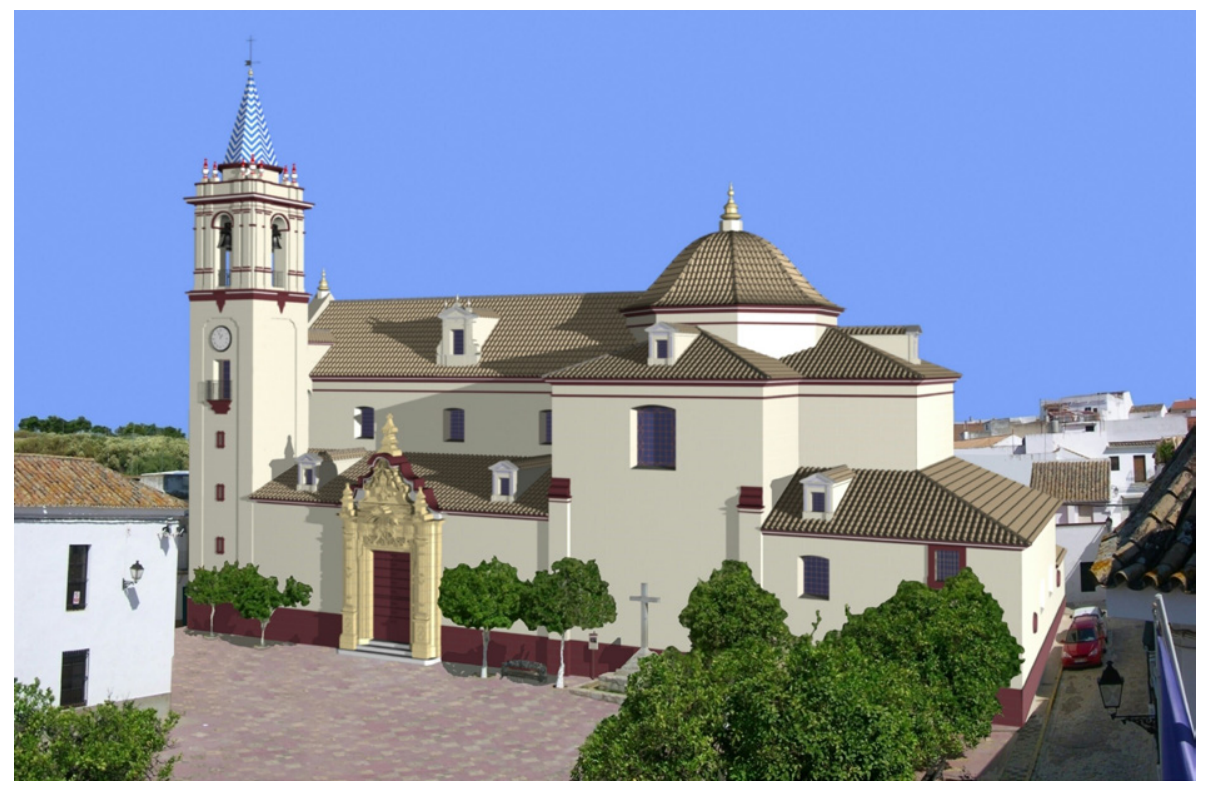

Figura 5. Volumetría hipotética de la iglesia trazada por Antonio de Figueroa. Dibujo: José Manuel Higuera Meléndez.

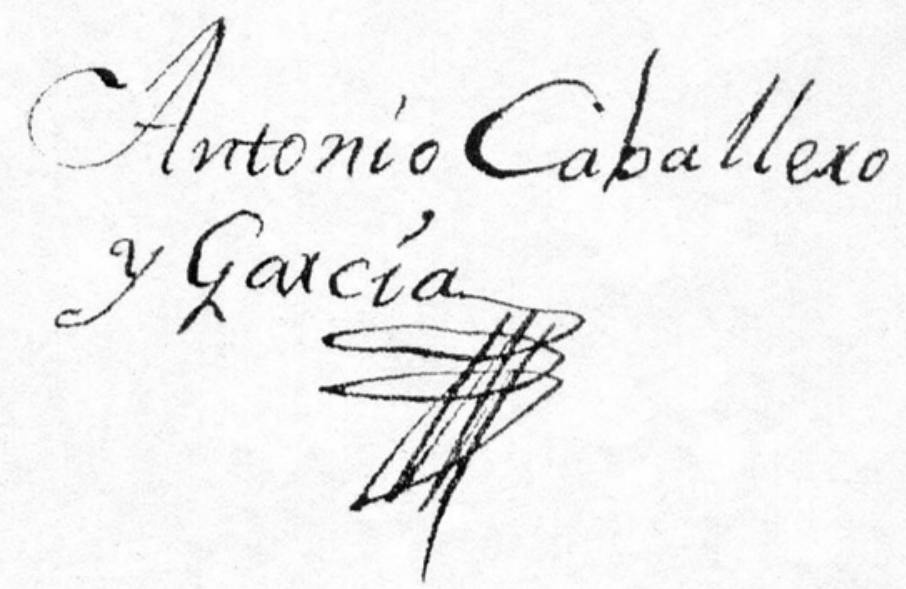

Figura 6. Firma de Antonio Caballero, 1781. 